\title{
DELIGHTING IN NATURAL BEAUTY: JOINT ATTENTION AND THE PHENOMENOLOGY OF NATURE AESTHETICS
}

\section{JOHAN DE SMEDT \& HELEN DE CRUZ}

\author{
Ghent University University of Oxford
}

\begin{abstract}
Empirical research in the psychology of nature appreciation suggests that humans across cultures tend to evaluate nature in positive aesthetic terms, including a sense of beauty and awe. They also frequently engage in joint attention with other persons, whereby they are jointly aware of sharing attention to the same event or object. This paper examines how, from a natural theological perspective, delight in natural beauty can be conceptualized as a way of joining attention to creation. Drawing an analogy between art and creation, we propose that aesthetic appreciation of nature may provide theists with a unique phenomenological insight into God's creative intentions, which are embodied in the physical beauty of creation. We suggest two directions in which this way of looking at the natural world can be fleshed out: in a spontaneous way, that does not take into account background information, and with the help of science.
\end{abstract}

\section{INTRODUCTION}

Although not all of nature is scenic, and some aspects of nature elicit negative aesthetic appraisals, people have a strong tendency to evaluate nature in positive aesthetic terms. ${ }^{1}$ This has been attested in several

\footnotetext{
${ }^{1}$ In this paper, we have chosen to focus on the positive aesthetic appraisal of nature that humans have. The increasing realization that stochastic (to humans) unpredictable processes have been crucial in the emergence of the natural world generates a number of theological challenges. Natural selection produces beauty but also generates what seem to be excessive amounts of animal and human suffering. Darwin (1860) remarked that the ichneumonidae, parasitic wasps that lay their eggs in the larvae of another species,
} 
cross-cultural studies (as, for instance, summarized in Ulrich 1993), conducted in East Asia, North America, Europe, Central Africa and Australia. Across these cultures, subjects evaluate natural scenes (even unspectacular ones) as beautiful, and they consistently judge urban scenes to be less attractive than natural scenes, especially if they lack water or vegetation. This finding is surprising, as, since the built environment was designed by humans for humans, one would prima facie expect humans to feel more aesthetically attracted to buildings than, say, trees. Aesthetic preference of nature is also reflected in real estate prices: properties with a view on natural scenery, such as mountains, lake or farmland are consistently more expensive than those that do not offer such a view, in countries as diverse as The Netherlands, China, and New Zealand (Jim \& Chen 2009). While the appreciation of nature differs across times and cultures, ${ }^{2}$ humans consistently find at least some aspects of nature beautiful. This tendency is not only present in adults, but also in young children in diverse cultures, indicating that it is robust and emerges early in development, prior to extensive cultural influence. Young children express a strong interest in and attraction to nature, e.g., in their drawings of animals and plants, even when they grow up in environments where their interaction with nature is limited (Kahn 1997). Exposure to nature also has a restorative effect on physical and mental health and increases psychological wellbeing (Velarde et al. 2007, Howell et al. 2011). Under experimental conditions, and from self-reports, we know that nature elicits a wide range of positive emotions, including enjoyment, awe and wonder (Shiota et al. 2007, Saroglou et al. 2008).

Authors like Basil of Caesarea (see section 5), C. S. Lewis (1949) and Frederic Tennant (1930) have explored how this positive appraisal of nature can be interpreted in a theistic framework. They regard the beauty of the natural world as theologically significant, as revealing something of God's nature and intentions. This paper will draw on cognitive science and environmental aesthetics to explore how aesthetic experience of nature

seem incompatible with a benevolent creator. This challenge needs to be taken seriously, and a full theological appraisal of natural beauty from the perspective of science should ultimately take into account natural evil as well. See e.g., Southgate 2008 for a theological exploration and attempt to meet this challenge.

2 The enjoyment of the mountains and the sea are recent phenomena in western culture; the Japanese concept of wabi-sabi, an aesthetic sensitivity to things that are imperfect, ephemeral and incomplete, such as a budding or decaying cherry blossom, does not have a corresponding concept in western nature aesthetics. 
can be regarded as a form of joint attention to creation with its creator. We do not present an aesthetic argument for the existence of God, but rather consider how natural beauty can be interpreted and experienced from a theistic point of view. After a brief methodological reflection, we look at art as a model of creation. Next, we consider the role of joint attention in nature appreciation, taking into account theoretical work in developmental psychology. We then discuss how natural beauty can be aesthetically enjoyed, using insights from environmental aesthetics.

\section{METHODOLOGICAL REFLECTION}

Analytic philosophy of religion attempts to answer questions like, 'Does God exist, and if so, what evidence do we have for his existence?' or 'What properties does God have?' To provide an answer to such questions, analytic philosophers rely on precise and clear definitions, clear-cut idealized scenarios and (often quite contrived) counterexamples, moving from premises to conclusions using established forms of argumentation. This approach dovetails with the methodology of systematic theology since the Middle Ages, which moves 'from what God can do to what he has done, rather than the other way round ... to move from the abstract to the concrete: from abstract omnipotence or absolute power to the economy of creation and redemption' (Gunton 1998: 147). This way of reasoning, while very useful, risks obscuring the fact that those who purportedly come to know God do so as concrete, embodied creatures, living in particular ecological (terrestrial) systems, and responding to creation in particular ways. Although many theistic philosophers, such as Augustine, have spoken of being in direct relationship with God, in practice such experiences tend to be reported after a considerable period of enquiry into the nature of the world. More generally, professed knowledge of God, or knowing God, tends to be connected in some way with knowledge of the world, or is even mediated through the world. ${ }^{3}$

In analytic philosophy of religion (e.g., Stump 2010, Trakakis 2008), there is a renewed appreciation that not all knowledge is easily translatable into a series of analytic statements, for instance, knowledge with phenomenological qualities or knowing how. It is therefore useful to explore alternative paths to philosophical knowledge in addition

3 As Bayer (2007: 152) puts it, 'ein wesentlich weltlich vermitteltes Verhältnis' (a relationship that is truly mediated through the world). 
to the idealized and abstract scenarios of many traditional arguments for theism. Rich narratives, for example, can provide knowledge by exemplification and illustration, rather than by conceptual analysis (Stump 2010, chapter 2). Narratives are irreducible to the precise, abstract propositions that tend to be used in formal reasoning processes, but they can provide an experiential knowledge that is more imprecise (analytically speaking) but that is also more evocative, memorable and illuminating. The epistemic value of narratives is not so much that they offer new facts (although they sometimes do), but that they offer a perception which allows listeners to see features of the world that would otherwise be invisible, what Wittgenstein called 'aspect perception', or 'seeing as' (see Schroeder 2009 for discussion). A pertinent illustration of aspect perception, and the knowledge it provides, can be found in That Hideous Strength, a novel by C.S. Lewis. It describes how Jane Studdock experiences a religious conversion in a garden. Even though there is no obvious change in her surroundings, her new perspective of the world means that she nonetheless perceives the garden in a radically different way:

Then, at one particular corner of the gooseberry patch, the change came. What awaited her there was serious to the degree of sorrow and beyond. There was no form nor sound. The mould under the bushes, the moss on the path, and the little brick border were not visibly changed. But they were changed. A boundary had been crossed. She had come into a world, or into a Person, or into the presence of a Person. Something expectant, patient, inexorable, met her with no veil or protection between (Lewis 1945: 441).

Appeals to natural beauty in theistic arguments capitalize on this effect of seeing the same phenomena in a different way. The observation that nature (or much of nature) is beautiful seems theologically significant, even though this observation cannot easily be moulded into a classic premise-conclusion style argument. Formal arguments from beauty (roughly of the form 'there is beauty in nature, therefore God exists') have been formulated in the past, but such arguments have few contemporary defenders (however, see Swinburne 2004: 190-191, for a brief discussion of beauty within his cumulative case for God's existence). There seems to be more scope for beauty as a source of knowledge of God, however, if it is not used in arguments of this kind. Our knowledge of natural beauty, because it has no clear boundaries, and does not have a context of artistic 
criticism, is inherently imprecise. Foster (1998: 132) calls this imprecise, phenomenological knowledge of aesthetic properties the 'ambient dimension of aesthetic value': it is the aesthetic response that cannot be put into words, the way we respond to the world 'as existentially embodied beings'. This intrinsic ambiguity, like the ambiguity and imprecision of narratives (from an analytic perspective), can be an advantage when we are thinking about matters that are inherently hard to grasp. The awe, wonderment and delight we feel when we walk in nature and contemplate aspects of it may even provide us with some immediate knowledge of the divine. ${ }^{4}$ It should be noted, however, that such attempts to use natural beauty as a road to knowledge about God do not replace formal arguments for the existence of God. Rather, they may provide a source for a different kind of knowledge about God (including phenomenological and personal knowledge) in addition to the analytic statements of recent philosophy of religion. ${ }^{5}$

\section{ART AS A MODEL OF CREATION}

Theologians traditionally understand creatio ex nihilo as a unique act, the effects of which have unfolded on a scale, scope and timeframe that surpasses human understanding. To get at least some grasp of what this event means, they have offered what are clearly understood to be imperfect analogies of God as being akin to a human creator. Such analogies gain a certain traditional warrant for their use in the scriptures of monotheistic faiths such as Christianity and Judaism. For example, Isaiah 45:9, Jeremiah 18 and Romans 9:21 refer to God as a potter, forming clay with his hands and potter's wheel, and Psalm 104 and Job 38 imagine him as an architect, laying out beams and cornerstones.

${ }^{4}$ Philosophers and theologians subsequently attempt to articulate the ineffable by developing concepts and arguments, but there always remains a gap between our experiences and our expressions of natural beauty (Heschel 1955, chapter 11).

${ }^{5}$ While we think appeals to beauty can co-exist with more formal natural theological arguments, Plantinga (2000: 175) explicitly pits non-inferential knowledge of God that natural beauty provides against arguments for God's existence: 'It isn't that one beholds the night sky, notes that it is grand, and concludes that there must be such a person as God: an argument like that would be ridiculously weak ... It is rather that, upon the perception of the night sky or the mountain vista or the tiny flower, these beliefs just arise within us. They are occasioned by the circumstances; they are not conclusions from them. The heavens declare the glory of God and the skies proclaim the work of his hands: but not by way of serving as premises for an argument.' 
These images are compatible with an understanding of creation in terms of an artwork, with the beauty of the natural world testifying to some kind of intentional and artistic divine action.

Can a valid analogy be drawn between creation and the work of an artist more generally, as these passages suggest? This question has attracted considerable scholarly attention, examples including the work of Hendry (1980, chapter 8) and Migliore (1991, chapter 5). Unsurprisingly, there are some obvious disanalogies. For example, a human artist cannot create ex nihilo but works instead with pre-existing materials. Aesthetic appreciation of nature also lacks the guidance of artistic context that we typically have for artworks, such as reference artworks or styles (Brady 1998). Finally, not all nature appears to be aesthetically valuable: there are parts of nature that are unscenic, dull or inhospitable (Saito 1998).

Despite these limitations, the analogy of creation as a work of art still unifies many traditional theological claims about God. For example, an artist enjoys freedom about whether to create and what to create, a freedom that is also attributed to God (albeit in an unimaginably greater sense). In art, as in the natural world, there is also a radical ontological distinction between creator and creation. Moreover, even in the absence of a satisfactory definition or understanding of what beautiful means, it is uncontroversial within philosophical aesthetics that as least some works of art and some aspects of nature possess that quality - the recent renewed attention to beauty in both art criticism and nature aesthetics (see De Clercq 2013, for review) testifies to this judgment.

If the analogy is at least partially valid, then it is possible to consider what kind of knowledge of the artist and hence also of the creator might be communicated by means of their respective works. For example, Gauguin depicted Tahitian women in oil paintings, pastel drawings, woodcarvings and woodcuttings, but in spite of the substantial differences of these media, his works exhibit an undeniable 'Gauguinesque' quality. In considering such qualities, Merleau-Ponty (1945: 212) has drawn attention to the unity of the mental and physical in art: works of art cannot be separated from what they express, e.g., the musical meaning of a sonata is inseparable from the sounds which are its vehicle. There is, in other words, no idea behind an artwork that is separate from it. Rather, the artwork is constitutive of the ideas through its physical characteristics, such as the sounds that constitute a sonata or the strokes of paint that make up a portrait. In a similar way, the beauty 
of creation arguably also constitutes and embodies God's creative ideas for the universe.

Of course, drawing attention to the beauty of creation invariably raises questions about these aspects of creation that do not seem beautiful, but here too the analogy of human artwork suggests some intriguing lines of thought. Although artworks are the expression of an artist's will and intentions, they also tend to take on some independence from their makers. Novelists often notice how characters acquire a will of their own, and how a story takes them in directions they did not foresee. As a famous example, Tolkien's Lord of the Rings was originally conceived as a light-hearted and brief sequel to The Hobbit, but turned out radically different. Artists often deliberately embrace this unpredictability, examples being the techniques of wet-on-wet (alla prima) in oil painting, and wet-into-wet in watercolour. Painters use these techniques to great effect (e.g., the lovely colour blends in Rembrandt and Velázquez that suggest depth and rich fabrics), but they are not entirely under their control; such effects are what painters call 'controlled accidents'. In the same way some aspects of creation may have come about through a kind of willed spontaneity, processes that are made possible but also given some causal independence by their creator.

\section{BEAUTY IN NATURE AND JOINT ATTENTION}

Given the possibility that natural beauty might reveal something of the nature and purposes of God, what kind of attention to nature might be required for this revelation to be manifest? In addressing this question, a few preliminary observations may be helpful. First, as far as we know, human beings are the only living creatures to produce works of art. Second, works of art are typically attended to not only by their creators but also by other persons. A helpful way to conceptualize our experience of natural beauty qua creation is by examining what cognitive psychologists call shared or joint attention, phenomena that are closely associated with second-person relatedness.

Over the past few decades, developmental and cognitive psychologists have studied the phenomenon of joint attention. While there is no agreement on a precise definition, there is consensus on what instances of shared experience constitute joint attention. For example, a toddler pointing excitedly at a hot air balloon, with her father also looking at the 
balloon and commenting on its colour, are engaged in joint attention. By contrast, two pedestrians, waiting to cross the road, are both attentive to the traffic light but may at that moment be oblivious to one another and so are not experiencing joint attention. Typically, people who are engaged in joint attention have a phenomenological sense of being emotionally and cognitively attuned to each other, for instance, they can both be disgusted or delighted by the same event, and realize that the other has the same reaction as they have. We could characterize joint attention approximately as social interactions where two or more agents not only jointly direct their attention toward an object, agent or event, but crucially, they share awareness of being in this state.

According to Tomasello and Carpenter (2007), joint attention is a crucial building block of human social relationships and of cumulative human culture, as it allows for the sophisticated social interactions that humans engage in, and for activities like teaching and other forms of explicit instruction. In spite of their sophisticated social cognition, chimpanzees and other great apes seem to lack joint attention (Call \& Tomasello 2008). In the first few months of life, social cognition in humans and chimpanzees is very similar: both human and chimpanzee infants prefer their mother's face and engage in dyadic interactions with her, such as smiling and mutual gazing. At around four to six months, members of both species become proficient at following the gaze of their mothers and other individuals. At about nine months, human infants develop the ability to share attention to a specific object with another person, e.g. by pointing out a cat that crosses the street. This 'nine-month revolution' (Tomasello \& Rakoczy 2003) does not occur in chimpanzees. In stark contrast to humans who from then on can engage in triadic interactions - caregiver, infant and object - chimpanzees learn from dyadic interactions only: they observe their mothers' behaviour carefully, and this helps them to reconstruct object-oriented actions for themselves. ${ }^{6}$ Moreover, chimpanzee infants, unlike human infants, do not look at the experimenter's face after following a gaze or pointing, which is one of the common elements of joint attention in human infants. Although some nonhuman animals are able to engage in some aspects

6 Tomonaga et al. (2004) not only observed many hours of exclusively dyadic interactions between chimpanzee infants and their mothers. They also repeatedly attempted to engage in triadic interactions with the infants, but failed to replicate the results obtained with human infants: for example, when they tried to engage in shared attention to a toy, chimpanzee infants would take it away to play by themselves. 
of joint attention, such as dogs, which are able to use eye direction and pointing gestures to retrieve hidden food rewards, joint attention seems to be of special importance in human cognition and culture, and if Tomasello and co-authors are correct, it is a crucial building block for human culture.

How is the phenomenon of joint attention related to art? This question has not received much attention in the cognitive psychological literature. Nevertheless, there is preliminary evidence that joint attention plays a crucial role in artistic understanding. Take the way in which young children eagerly show pictures they have drawn to their parents ('Look, a car!') and point out relevant features. Also, both the production and appreciation of art involve attention: children and adults spontaneously take the 'design stance' (a perspective by which a work is evaluated in terms of its intended function and identity) when they interpret artworks. Two-year-olds, for example, are more likely to call a vaguely zoomorphic spot 'a bear' when they learn that someone carefully painted it than when they hear it was the result of someone accidentally kicking over a bucket of paint (Gelman \& Ebeling 1998). Similarly, preschoolers and adults recognize an irregular piece of stone as a sculpture when they hear it was deliberately chiselled and polished, but call it a rock if they learn it has this form because someone hurled it against a wall (Gelman \& Bloom 2000). Literary artists also take into account our expectations and mental states by keying in on features they know will grasp our attention. For example, Jane Austen's astute descriptions of awkward social situations reveal her mischievous delight in human shortcomings, giving her readers a sense of implicit joint attention and complicity. Austen comments on and draws our attention to 18th-century social situations, such as how to get a suitable marriage partner if one has no money. We share in her thoughts about these situations and how her characters experience them by the way she fleshes them out in her novels.

Such interpretations are made easier if there is background information available about the creator's intentions in producing the artwork. Threeand four-year-olds already infer intentions of absent artists by relying on background information, e.g., when two scribbles are presented as an elephant and a mouse drawn by a child with a broken arm, they reasonably infer that the smallest scribble represents the mouse (Bloom \& Markson 1998). Indeed, a standard model in contemporary philosophy of art is the psychohistorical approach (Levinson 1993, Bullot \& Reber 2013), which focuses on the importance of this background information. 
But what if no background information is available? According to Lehrer (2006), we still gain ineffable and immediate knowledge from an artwork by direct interaction with it, a kind of knowledge that cannot be obtained by even the most exhaustive linguistic description in the absence of the artwork itself. For example, the bold colour contrasts and whirling brush strokes of Vincent Van Gogh's Starry Night (1889) reveal something about his artistic intentions. The painting is an implicit invitation to share Van Gogh's mode of attending the scene, an experience that could not be replicated by written descriptions, even if we had a detailed linguistic account of his intentions, e.g., in letters to his brother Theo (De Smedt \& De Cruz 2013). ${ }^{7}$ To give an extreme example, Paleolithic cave paintings and sculptures are artworks for which we have no biographical and very little cultural information, and their meaning and the purposes for which they were made remain topics of debate. Nevertheless, despite our lack of knowledge, the physical exposure to the artworks themselves is overwhelming, and they speak to a contemporary audience in a very direct way. The lustre and detail of small ivory sculptures of mammoths, horses and birds express with immediacy the care their makers took in their production (De Smedt \& De Cruz 2011). This observation accords well with our phenomenological approach to joint attention: instead of conceiving of artistic intentions as something separate that we have to reconstruct painstakingly by relying on background information of the artist's life and context, the intentions of an artist are not separable from the way she physically expresses them in paint, sounds or words. Because some of these intentions have been embodied in the media they are expressed in, it is still possible to engage in a kind of joint attention with these long-deceased artists. In the following sections, we consider how this way of joining attention to art can be applied to the appreciation of nature within a theistic framework.

7 There is something about an artwork itself and what it conveys that cannot be translated in any other way. To wit, we have ample information about the ancient Greek painter Apelles ( $4^{\text {th }}$ century BCE) in written sources like Pliny the Elder's Naturalis Historia, up to the techniques he used to achieve depth. But because no works survive, and no paintings can be reliably identified as faithful copies of his original output, we do not really know anything about Apelles' creative intentions. This is because an artwork is constitutive of the ideas it expresses. Our direct experience with an artwork remains the source of our understanding of it and ultimately issues from it, no matter how many layers of interpretation it subsequently receives (Merleau-Ponty 1962). 


\section{JOINT ATTENTION TO CREATION IN THE ABSENCE OF BACKGROUND INFORMATION}

We will now discuss aesthetic appreciation of nature in the absence of background information, such as revealed theology or science. If some aspects of joint attention with another human person are possible by means of a work of art, is this also possible with God in the case of creation? What can sustained attention to nature alone teach about God?

One model in nature aesthetics, offered by Carroll (1993) examines the visceral and immediate response that people have to nature to understand our aesthetic appraisal of it. Even if we have little or no background knowledge about the landscape we find ourselves in, we can be moved by the grandeur of a waterfall, the lazy twirl of an autumn leaf, a lonely poppy in a field of grain. Aesthetic enjoyment of nature is inherently participatory, since we are also part of nature and part of the scene we are contemplating. The experience is also multi-sensory: the forlorn cries of seagulls, the feeling of sunlight and wind, the taste of salt in the air, the waves crashing and gritting all contribute to an aesthetic experience of a rocky seashore. This participatory experience allows humans to appraise nature with little background information about what it is they are experiencing.

In the psychology of nature appreciation, awe is a positive emotion that is frequently cited in response to natural beauty. In studies that require participants to keep a diary, being in a vast landscape, like the Grand Canyon, seems to be the prime elicitor of awe (Shiota et al. 2007). The main psychological model for awe is Keltner and Haidt's (2003) prototype model: awe is elicited when we are confronted with something that is vast and that we attempt, but fail, to accommodate. Vastness is the experience of something being much larger in relation to oneself. Sundararajan (2002) has expanded this model by adding self-reflexivity. Awe frequently brings about a self-reflective attitude: while in awe, we perceive ourselves as experiencing a sense of smallness in relation to what is contemplated, mixed with a paradoxical sense of greatness. This may be combined with a kind of joyful willingness to be wholly absorbed by, or surrendered to this experience, what Otto (1923, 21-22) calls 'selfdepreciation' The sense of awe captures well the sentiment expressed in a Hasidic adage that a person should always carry two pieces of paper in his pocket, one that says, 'I am but dust and ashes', and the other that says 'The world was created for me' (Wettstein 2012: 32). This duality of 
feeling both humbled and elevated has been confirmed in self-reports of aesthetic experiences of natural beauty, indicating that participants feel a sense of smallness or personal insignificance, a decreased awareness of day-to-day concerns, a sense of something greater than themselves, and a desire for the experience to continue (Shiota et al. 2007). When in a state of awe, humans feel small and insignificant, yet elevated and exhilarated. This state of mind is thus unlike other humbling emotions like shame or regret which make one feel both small and miserable (Keltner \& Haidt 2003). People who experience awe sense a heightened connectivity to the world around them, a sense of the tremendous value of the natural world, and a lack of pettiness (Shiota et al. 2007).

How, then, does the sense of awe relate to the model of joint attention? By itself, awe does not seem to have a necessary connection to theistic awareness. In one study that probed feelings of awe in atheists, a majority of atheists reported having felt awe and being part of something greater than themselves, suggesting that atheism and awe are psychologically compatible (Caldwell-Harris et al. 2011). Nevertheless, there is some evidence of a close psychological connection between awe and religiosity: empirical studies indicate that the experience of awe, as elicited by scenes of natural beauty, increases religious belief (Valdesolo \& Graham, in press). Although awe does not automatically trigger belief in God, for a theist, it can strengthen theistic belief. The initial sense of God may be innate, as in Calvin's sensus divinitatis, or inferred as a conclusion of reason to a particular kind of first cause, or simply entertained as a hypothesis in the manner of Pascal's Wager. Once the possibility of God is raised, however, the contemplation of some awesome aspect of nature as possibly the work of God may have a multiplier effect in two senses: a heightened interest in this aspect of nature and an increased sense of divine presence. ${ }^{8}$

${ }^{8}$ Emil Brunner argued that the doctrine of the imago Dei entails that there is a 'point of contact' where God reveals himself to us (see Smedes forthcoming, for review). However, he left the exact nature of this point of contact unspecified. The centrality of awe in religious life and its importance in cultivating a religious sensibility are good candidates for this: from a theistic perspective, delight in creation allows one to join attention with God, and thus share in his joy. Wettstein (2012) has argued that this sense of awe is a basic feature of religious life that allows one to cultivate a religious sensibility even if one does not hold an explicit belief in God - awe is more central to religious belief than (detached) metaphysical attitudes about God's existence. 
We will now consider how theologians have explored this visceral, intuitive response to natural beauty as a way of gaining knowledge of God. The 18th-century theologian Jonathan Edwards (see Lane 2004, for review) wrote extensively about the spontaneous, untutored appreciation of nature. He argued that by being attentive to natural beauty, and by delighting in it, humans develop a sensus suavitatis, a perceptual mode that gives the believer access to a religious sensibility that integrates and heightens ordinary sense experience. Nature is a school of desire that provides humans with a multisensory knowledge of God through the beauty of his creation. Basil of Caesarea, too, exclaims his visceral delight in creation throughout his commentary on Genesis (Schaefer 2001). Likewise, the Jewish theologian Abraham Heschel (1955: 74) considers a cultivated sense of awe of natural beauty as a prerequisite for faith: 'Awe ... is more than an emotion; it is a way of understanding.' Thus, our sense of awe and wonderment at nature

enables us to perceive in the world intimations of the divine, to sense in small things the beginning of infinite significance, to sense the ultimate in the common and the simple; to feel in the rush of the passing the stillness of the eternal (Heschel 1955: 75).

In our everyday lives, we are caught up in thinking about the world around us from a particular point of view, and habitually we consider our personal perspective as the whole picture. However, Heschel (1955: 75) argues that through awe, we can become aware of what escapes us, we acquire 'the ability to look at all things from the point of view of God'. Recent empirical studies (e.g., Rudd et al. 2012) indicate that experiences of awe alter time perception; it brings people into the present moment, and this acute awareness of the present makes them feel that they have more time available. As Lewis wrote,

[T] he Present is the point at which Time touches Eternity. Of the present moment, and of it only, humans have an experience analogous to the experience which [God] has of reality as a whole; in it alone, freedom and actuality are offered them (Lewis 1942: 75).

Although these theologians write within the confines of their respective traditions, the delight in natural beauty they describe is unmediated and spontaneous. For them, the beauty of nature is not merely a semiotic system that refers to beauty beyond the world (a reflection of the creator's beauty); it also points to the inherent value of creation, the beauty in 
and of the world. Theists can thus interpret awe as the state of mind in which they can share attention with God over at least some aspects of creation. As in ordinary forms of joint attention, this does not mean they literally can see things the way God does, anymore than a toddler joining attention with her father over a horse in a meadow gets access to all her father's knowledge of or earlier experiences with horses. However, by sharing attention she can get a phenomenological sense of joining minds with her father, and becomes aware of the features of the horse that capture his attention. This conceptualization of awe as joint attention over creation provides a new way of interpreting the phenomenological experience of aesthetic nature appreciation, as when we ponder the empty expanse of the prairie or the intricacy of frozen cobwebs.

\section{JOINT ATTENTION TO CREATION WITH BACKGROUND INFORMATION}

Having reviewed how awe of nature can provide theists with an unmediated sense of joining attention with God to creation, we now discuss how background information could further inform and guide this experience. An obvious source would be scripture, and indeed, the Bible contains several passages that provide a context for nature appreciation, e.g., Genesis 1-2 and Psalms 19 and 104. The natural theologian can additionally turn to the Book of Nature as studied by science, as a way to sustain and ground aesthetic appreciation of nature. A deep appreciation and sense of wonder for the beauty of the natural world has been an important driving force, both in natural theology and in scientific practice. Although contemporary natural theological arguments are typically rigorously formulated, they originate in prescientific sentiments, including an admiration for the beauty of creation. As Evans (2010) argues, a sense of wonderment for nature underlies natural theological arguments, even the most rigorously formulated ones. Scientific and aesthetic approaches to nature are not mutually exclusive, but can enrich and strengthen each other, see e.g., Paley's (1802) scientifically-informed natural theology, which exudes his love for nature; an avid fisherman, he greatly enjoyed spending time outdoors. Next to the fertile relationship between aesthetic appreciation of nature and science, we also focus on science as background information because the science-based approach has been very influential in nature aesthetics: Carlson (e.g., 1979, 1995) 
has argued that scientific knowledge of the natural world is as vital to the aesthetic appreciation of nature as art critical (historical, biographical) contexts are for the appreciation of artworks.

The science-based approach in nature aesthetics can interlock with a natural theological approach to beauty, where science can provide background information about creation. One way in which science can do this is by providing clues that can heighten aesthetic experience. Edwards (2012: 70) discusses a scientific awareness of nature as a form of 'beauty skills', skills that enrich our experiences, and that allow us to see aspects of the beauty of creation we would otherwise overlook. Although it is possible to enjoy forests only for their shapes, colours and sounds, and to be totally oblivious of the taxonomy of the species one encounters, forests are dynamic entities, shaped by ancient and continuing evolutionary and ecological processes. Their enormous time scale is part of their objective reality, and realizing this can contribute to our aesthetic appreciation. Without scientific knowledge, there is little awareness of this time dimension of evolution, geology and other processes that are not immediately perceptible to the untutored. Science can help us appreciate what is not evident, e.g., the remarkable efficiency of photosynthesis can add a sense of wonder when we behold a forest canopy (Rolston 1998). Evolutionary theory and geology afford us a very different way of encountering the natural world compared to our forebears: e.g., they could not know that erosion by long-vanished glaciers gave rise to the stunning limestone pavements in the Yorkshire Dales.

The science-based approach to nature aesthetics by itself does not favour a theistic point of view. Many atheistic authors (e.g., Dawkins 1998) have reflected on the beauty of the natural world, and on how their scientific understanding has enhanced this experience. However, for theists, the aesthetic appraisal of nature has epistemic value. From a theistic perspective, the beauty manifest in the natural world is not an accident but a consequence of the work of divine intellect, and thus it can say something about divine creative intentions. We saw in the previous section how the aesthetic experience of nature can be a visceral response, in the absence of background information. Science provides background information that can help to interpret and colour this aesthetic experience, and insights from science can help to bring experiences into focus that are otherwise fleeting and would be difficult to interpret. 
We conclude by commenting briefly on two key insights of scientific practice that are relevant for the aesthetic appraisal of nature: its diversity and its inherent stochasticity. When asked what one could conclude about the nature of the creator from a study of his creation, the biologist Haldane allegedly quipped, 'an inordinate fondness for beetles'. The original quote ${ }^{9}$ is less gripping, but the general point remains: given the richness and diversity of the natural world, it is hard to maintain a purely anthropocentric interpretation of natural beauty. In the past, theologians have tended to interpret the natural order in anthropocentric terms, with humans at the summit of the created natural world. Nowadays, when we consider the tree of life from its earliest beginnings, we no longer think of this tree as one straight stem, steadily growing to its pinnacle, humanity, but rather as a large bush with many small twigs, of which we are but one. For theists, a natural way to interpret this is that God delights in the diversity and beauty of nature in its many forms, extending back deep in time. For example, McNamara et al. (2012) reconstructed the original colours of fossil beetles that lived between 15 and 47 million years ago. Their iridescent blues, greens and golds were obviously not designed for human delight: these beetles were beautiful long before humans were there to behold them.

An aesthetic appreciation of nature through science not only cautions us against an overtly anthropocentric interpretation of nature, it may also provide some insights into God's artistic intentions. The openness, stochasticity and freedom of creation, as exemplified by evolution through natural selection, can be a further source of aesthetic enjoyment. Organisms are not just passive objects in evolutionary history, but dynamically shape their environment, as active participants. Such interactions between organisms and environment can afford a sense of aesthetic delight: termite nests shape their own microclimate, beaver dams impact the wider ecology, increasing species diversity. Science helps uncover less obvious examples, such as the role of cyanobacteria in creating our oxygen-rich atmosphere. Like controlled accidents in painting, stochasticity in creation can be intentional; 'God can will accidental events as accidental', as Jaeger (2012: 87) puts it. Such controlled accidents bring about remarkable results, with manifold anatomical and cognitive specializations. Such outcomes are beautiful, and the dignity

9 ' $[\mathrm{T}]$ he creator would appear as endowed with a passion for stars, on the one hand, and beetles on the other' (Haldane 1947: 239). 
bestowed on their having a certain freedom and spontaneity of their own may be part of that beauty.

Acknowledgments. We thank Andrew Pinsent, John Schneider and Howard Wettstein for helpful comments on an earlier version of this paper. This research has been financially supported by the British Academy and Ghent University.

\section{BIBLIOGRAPHY}

Bayer, Oswald. 2007. Martin Luthers Theologie (Tübingen: Mohr Siebeck) Bloom, Paul, and Lori Markson. 1998. 'Intention and Analogy in Children's Naming of Pictorial Representations', Psychological Science, 9: 200-204

Brady, Emily. 1998. 'Imagination and the Aesthetic Appreciation of Nature', Journal of Aesthetics and Art Criticism, 56: 139-147

Bullot, Nicolas J., and Rolf Reber. 2013. 'The Artful Mind Meets Art History: Toward a Psycho-Historical Framework for the Science of Art Appreciation', Behavioral and Brain Sciences, 36: 123-180

Caldwell-Harris, Catherine L., Angela L. Wilson, Elizabeth LoTempio, and Benjamin Beit-Hallahmi. 2011. 'Exploring the Atheist Personality: Wellbeing, Awe, and Magical Thinking in Atheists, Buddhists, and Christians', Mental Health, Religion \& Culture, 14: 659-672

Call, Josep, and Michael Tomasello. 2008. 'Does the Chimpanzee Have a Theory of Mind? 30 Years Later', Trends in Cognitive Sciences, 12: 187-192

Carlson, Allen. 1979. 'Appreciation and the Natural Environment', Journal of Aesthetics and Art Criticism, 37: 267-275

Carlson, Allen. 1995. 'Nature, Aesthetic Appreciation, and Knowledge', Journal of Aesthetics and Art Criticism, 53: 393-400

Carroll, Noel. 1993. 'On Being Moved by Nature: Between Religion and Natural History', in Salim Kemal and Iwan Gaskell, eds., Landscape, Natural Beauty and the Arts (Cambridge: Cambridge University Press), pp. 244-266

Darwin, Charles. 1860. Letter to Asa Gray, 2 May 1860. Available at: <http:// www.darwinproject.ac.uk/entry-2814> [accessed 09/12/13]

Dawkins, Richard. 1998. Unweaving the Rainbow: Science, Delusion and the Appetite for Wonder (Boston: Houghton Mifflin)

De Clercq, Rafael. 2013. 'Beauty', in Berys Gaut and Dominic McIver Lopes, eds., The Routledge Companion to Aesthetics (3rd ed.) (Abingdon: Routledge), pp. 299-308

De Smedt, Johan, and Helen De Cruz. 2011. 'A Cognitive Approach to the Earliest Art', Journal of Aesthetics and Art Criticism, 69: 379-389

De Smedt, Johan, and Helen De Cruz. 2013. 'The Artistic Design Stance and the Interpretation of Paleolithic Art', Behavioral and Brain Sciences, 36: 139-140 
Edwards, L. Clifton. 2012. 'Artful Creation and Aesthetic Rationality: Toward a Creational Theology of Revelatory Beauty', Theology Today, 69: 56-72

Evans, C. Stephen. 2010. Natural Signs and Knowledge of God. A New Look at Theistic Arguments (Oxford: Oxford University Press)

Foster, Cheryl. 1998. 'The Narrative and the Ambient in Environmental Aesthetics', Journal of Aesthetics and Art Criticism, 56: 127-137

Gelman, Susan A., and Paul Bloom. 2000. 'Young children are sensitive to how an object was created when deciding what to name it', Cognition, 76: 91-103

Gelman, Susan A., and Karen S. Ebeling. 1998. 'Shape and representational status in children's early naming', Cognition, 66: B35-B47

Gunton, Colin. 1998. The Triune Creator: A Historical and Systematic Study (Grand Rapids: Eerdmans)

Haldane, J.B.S. 1947. What is Life? (New York: Boni and Gaer)

Hendry, George S. 1980. Theology of Nature (Philadelphia: Westminster)

Heschel, Abraham Joshua. 1955. God in Search of Man: A Philosophy of Judaism (London: Souvenir, 2009)

Howell, Andrew J., Raelyne L. Dopko, Holli-Anne Passmore, and Karen Buro. 2011. 'Nature Connectedness: Associations with Well-Being and Mindfulness', Personality and Individual Differences, 51: 166-171

Jaeger, Lydia. 2012. What the Heavens Declare: Science in the Light of Creation (Eugene, Or.: Wipf and Stock)

Jim, C.Y. and Wendy Y. Chen. 2009. 'Value of Scenic Views: Hedonic Assessment of Private Housing in Hong Kong', Landscape and Urban Planning, 91: 226234.

Kahn, Peter H. 1997. 'Developmental Psychology and the Biophilia Hypothesis: Children's Affiliation with Nature', Developmental Review, 17: 1-61

Keltner, Dacher, and Jonathan Haidt. 2003. 'Approaching Awe, a Moral, Spiritual, and Aesthetic Emotion', Cognition and Emotion, 17: 297-314

Lane, Belden C. 2004. 'Jonathan Edwards on Beauty, Desire, and the Sensory World', Theological Studies, 65: 44-72

Lehrer, Keith. 2006. 'Knowing Content in the Visual Arts', in Matthew Kieran and Dominic MacIver Lopes, eds., Knowing Art: Essays in Aesthetics and Epistemology (Dordrecht: Springer), pp. 1-18

Levinson, Jerrold. 1993. 'Extending Art Historically', Journal of Aesthetics and Art Criticism, 51: 411-423

Lewis, C.S. 1942. The Screwtape Letters (London: HarperCollins, 2002)

Lewis, C.S. 1945. That Hideous Strength (London: HarperCollins, 2005)

Lewis, C.S. 1949. 'The Weight of Glory', in The Weight of Glory and Other Addresses (London: HarperCollins, 2001), pp. 25-46

McNamara, Maria E., Derek E.G. Briggs, Patrick J. Orr, Heeso Noh, and Hui Cao. 2012. 'The Original Colours of Fossil Beetles', Proceedings of the Royal Society B, 279: 1114-1121 
Merleau-Ponty, Maurice. 1945. Phenomenology of Perception, trans. by Colin Smith (London: Routledge, 2002)

Merleau-Ponty, Maurice. 1962. 'Eye and Mind', trans. by Michael Smith, in Galen A. Johnson, ed., The Merleau-Ponty Aesthetics Reader: Philosophy and Painting (Evanston, IL: Northwestern University Press, 1993), pp. 121-149

Migliore, Daniel L. 1991. Faith Seeking Understanding: An Introduction to Christian Theology (Grand Rapids, MI: Eerdmans)

Otto, Rudolf. 1923. The Idea of the Holy: An Inquiry into the Non-Rational Factor in the Idea of the Divine and its Relation to the Rational, trans. by John W. Harvey (London: Humphrey Milford)

Paley, William. 1802. Natural Theology or Evidence for the Existence and Attributes of the Deity, Collected from the Appearances of Nature, M.D. Eddy and D. Knight, eds. (Oxford: Oxford University Press, 2006)

Plantinga, Alvin. 2000. Warranted Christian Belief (New York: Oxford University Press)

Rolston, Holmes. 1998. 'Aesthetic Experience in Forests', Journal of Aesthetics and Art Criticism, 56: 157-166

Rudd, Melanie, Kathleen D. Vohs, and Jennifer Aaker. 2012. 'Awe expands people's perception of time, alters decision making, and enhances wellbeing, Psychological Science, 23: 1130-1136

Saito, Yuriko. 1998. 'The Aesthetics of Unscenic Nature', Journal of Aesthetics and Art Criticism, 56: 101-111

Saroglou, Vassilis, Coralie Buxant, and Jonathan Tilquin. 2008. 'Positive Emotions as Leading to Religion and Spirituality', Journal of Positive Psychology, 3: 165-173

Schaefer, Jame. 2001. 'Appreciating the Beauty of Earth', Theological Studies, 62: 23-52

Schroeder, Severin. 2010. 'A Tale of Two Problems: Wittgenstein's Discussion of Aspect Perception', in John Cottingham and Peter Hacker, eds., Mind, Method and Morality: Essays in Honour of Anthony Kenny (Oxford: Oxford University Press), pp. 352-371

Shiota, Michelle N., Dacher Keltner, and Amanda Mossman. 2007. 'The Nature of Awe: Elicitors, Appraisals, and Effects on Self-Concept', Cognition and Emotion, 21: 944-963

Smedes, Taede A. forthcoming. 'Emil Brunner Revisited: On the Cognitive Science of Religion, the Imago Dei, and Revelation', Zygon: Journal of Religion and Science

Southgate, Christopher. 2008. The Groaning of Creation: God, Evolution, and the Problem of Evil (Louisville, KY: Westminster John Knox Press)

Stump, Eleonore. 2010. Wandering in Darkness: Narrative and the Problem of Suffering (Oxford: Oxford University Press) 
Sundararajan, Louise. 2002. 'Religious Awe: Potential Contributions of Negative Theology to Psychology, "Positive" or Otherwise', Journal of Theoretical and Philosophical Psychology, 22: 174-197

Swinburne, Richard. 2004. The Existence of God (6th ed.) (Oxford: Clarendon Press)

Tennant, Frederic. 1930. Philosophical Theology (volume 2): The World, the Soul, and God (Cambridge: Cambridge University Press)

Tomasello, Michael, and Malinda Carpenter. 2007. 'Shared Intentionality', Developmental Science, 10:121-125

Tomasello, Michael, and Hannes Rakoczy. 2003. 'What Makes Human Cognition Unique? From Individual to Shared to Collective Intentionality', Mind and Language, 18: 121-147

Tomonaga, Masaki, Masayuki Tanaka, Tetsuro, Matsuzawa, Masako MyowaYamakoshi, Daisuke Kosugi, Yuu Mizuno, Sanae Okamoto, Masami K. Yamaguchi, and Kim A. Bard. 2004. 'Development of social cognition in infant chimpanzees (Pan troglodytes): Face recognition, smiling, gaze, and the lack of triadic interactions', Japanese Psychological Research, 46: 227-235 Trakakis, Nick. 2008. The End of Philosophy of Religion (London: Continuum)

Ulrich, Roger S. 1993. 'Biophilia, Biophobia, and Natural Landscapes', in Stephen R. Kellert and E.O. Wilson, eds., The Biophilia Hypothesis (Washington, DC: Island Press), pp. 73-137

Valdesolo, Piercarlo and Jesse Graham. in press. 'Awe, Uncertainty, and Agency Detection', Psychological Science

Velarde, M.D., G. Fry, and M. Tveit. 2007. 'Health Effects of Viewing Landscapes Landscape Types in Environmental Psychology', Urban Forestry \& Urban Greening, 6: 199-212

Wettstein, Howard. 2012. The Significance of Religious Experience (Oxford: Oxford University Press) 